\title{
Encouraging Active Commuting through monitoring and analysis of commuter travel method habits
}

\author{
Salim Hasshu \\ Centre of Computational Intelligence \\ De Montfort University \\ Leicester, LE1 9BH, UK \\ p08277628@myemail.dmu.ac.uk \\ Benjamin N. Passow \\ DMU's ITS Research Group (DIGITS), \\ Centre of Computational Intelligence, \\ De Montfort University \\ Leicester, LE1 9BH, UK \\ benpassow@ieee.org
}

\author{
Francisco Chiclana \\ Centre of Computational Intelligence \\ De Montfort University \\ Leicester, LE1 9BH, UK \\ chiclana@dmu.ac.uk \\ David Elizondo \\ DMU's ITS Research Group (DIGITS), \\ Centre of Computational Intelligence, \\ De Montfort University \\ Leicester, LE1 9BH, UK \\ elizondo@dmu.ac.uk
}

\begin{abstract}
The aim of this research is to understand and encourage healthier commuter travel method habits. Commuters who choose healthier travel, such as; walking, cycling or public transport methods, are known as Active Commuters (AC). However current literature suggests private car use is still the dominant method of transport. Additionally, there are very few AC monitoring and analysis applications for mobile devices, which lead to the following research question; "If commuters are able to monitor and analyse their travel habits, would this encourage them to choose AC methods?" In this work we propose a novel methodology that investigates this question. This technique was implemented and tested as an Android mobile application, giving valuable insights into AC habits. The Active Commute Tracker (ACT) mobile application was developed to include the following three components: (1) Commute Transport Method Calculation component, (2) Health component and (3) Sharing component. ACT allows users to monitor and record their commute method, distance travelled in total and commute health analysis. A basic version of this data can be shared on Facebook. Users tested the application for a set number of days and provided feedback of functionality, but more importantly whether or not it encouraged AC. Feedback from users confirmed that there is a demand for an application of this nature. No user was discouraged as a direct result of ACT.
\end{abstract}

Index Terms - Active Commuting, Travel, Mobile Application.

\section{INTRODUCTION}

Commuting for many of us is an important part of our day to day life. The choices we make in the method of transport can have positive and negative effects on our wellbeing as well as on the environment (Frank et al, 2004; Department of Health, 2009; Government Office of Science, 2007; Mokdad et al, 2001; Dora, 2007). With over half of Britons estimated to be obese by 2050 (foa.org, 2013), one common suggestion to tackle this issue is appropriate physical activity.
It is widely recognised that meeting the recommended amount of physical activity contributes towards reductions in coronary heart disease, obesity, hypertension, depression and even anxiety (Department of Health, 2009). Unfortunately the by-product of our modern 'obesogenic' lifestyles promotes the abundance of high calorie foods, readily available 'motorised transportation' and potential for a 'predominantly inactive lifestyle' (Government Office of Science, 2007). Less than half the population in the UK engages in the recommended amount of moderate intensity physical activity (MIPA) a day (National Statistics, 2014).

MIPA can be incorporated into daily commute. Physical activity as a means of transport, such as cycling or walking to work, is associated with low $\mathrm{CO} 2$ emissions in urban areas. Those who choose these methods of transport are known as Active Commuters (AC). More commuters choosing to be AC can have direct benefits, such as improvement in personal physical health, as well as indirect benefits, such as reduction in density of traffic and, consequently, improved air quality in urban areas. However, private vehicle use is steadily increasing (Cameron et al, 2003), prohibiting sustainability in economic performance, social welfare and environmental resilience (Batterbury, 2003). This has been an increasingly concerning issue worldwide for many years.

With the ever increasing use of private vehicles, continual reduction in air quality, general lack of MIPA and congestion in road traffic networks, there has never been a more appropriate time encouraging commuters to choose AC.

\section{RESEARCH}

Key areas that require further investigation have been identified, which are divided into: (A) Commuter Travel Methods, (B) Health, (C) Active Commuting and (D) Application. Each section provides understanding in development towards encouraging AC. 


\section{A. Commuter Travel Methods}

There are many different methods in which a commuter can choose to travel. The method a commuter chooses can be determined by a number of factors, of which the commuter might have full control or none at all.

Ortuzar \& Willumsen (Ortuzar \& Willumsen, 1999) present a number of key factors to consider by commuters before choosing their method of commute, which include;

\section{Characteristics:}

- Purpose of the trip: e.g., the commute to work is normally easier to undertake by public transport because of its regularity;

- Time commute is undertaken: late trips are more difficult to undertake by public transport;

- The trip is taken alone or with others.

\section{Quantitative factors:}

- Travel time: in-vehicle, waiting and walking times;

- Monetary costs: fares, tolls, fuel and other costs;

- Parking: Availability and cost of parking;

- Reliability of travel time and regularity of service.

\section{Qualitative factors}

- Convenience and comfort;

- Safety: protection, security;

- Demands of the driving task;

- Opportunities of activities during travel, e.g. reading.

However there are advantages and disadvantages for the choices commuters make on the method of travel. Advantages can be; time, financial and/or health benefits, with disadvantages potentially being the same factors.

Research shows that the dominant method of travel worldwide is still private motor vehicle (Cameron et al, 2003; Wen et al, 2006) and Department for Transport (DfT, 2011) confirms that private vehicle being highest overall commute method in Britain. Although the increase rate has reduced, the rise in cars in Britain's roads still presents a number of issues, such as; congestion, air pollution and noise pollution. Many argue that driving private vehicles to work is the easiest method. However, alternative methods may only differ slightly in characteristics, yet provide personal (direct) and global (indirect) benefits. Motivation for using private vehicles, instead of AC, extends beyond utilitarian reasons and into symbolic and affective motives (Steg, 2004; Gardner \& Abraham, 2007; Bergstad et al, 2011).

In order to understand what motivates commuters to choose private vehicles, Steg (Steg, 2004) examines private vehicle ownership beyond previous behavioural studies, which only focused on instrumental factors of vehicle ownership, such as; convenience and flexibility. Expanding from just utilitarian purposes, some authors argue that commuters perceive vehicles as more than just a private motorised transportation tool (Mokhtarian
\& Salomon, 2001; Mokhtarian et al, 2001). Commuters can express themselves through vehicle ownership, as many consider driving as adventurous, thrilling and pleasurable (Steg, 2004) resulting in undirected private motorised transportation without transport demand (Mokhtarian \& Salomon, 2001; Mokhtarian et al, 2001). This implies that for many, vehicle ownership has symbolic and affective factors as well as a motorised transportation tool.

Steg (Steg, 2004) tested this proposition by applying vehicle ownership factors into Dittmar's model of material possessions. Dittmar suggests that the use of material goods fulfils three functions to the user: instrumental, symbolic, and affective. With this in mind, Steg applies this reasoning onto vehicle ownership:

Instrumental - enables activity;

Symbolic - an expression of themselves;

Affective - a connection towards desire and satisfaction.

Steg's survey of 113 random commuters showed that private vehicle use as a commuting method was most strongly related to symbolic and affective motives, such as the desire for control, and not as strongly to instrumental motives, (Steg, 2004; Gardner \& Abraham, 2007; Bergstad et al., 2011).

These results may apply a level of difficulty in encouraging commuters to be AC. Expressing the quality aspects of AC could be the next step towards encouraging commuters out of their private vehicles. The ownership and control experienced with private vehicle ownership could be applied to the commute itself, by allowing monitoring and analysis of a commuters travel habit. By owning the journey itself commuters could be encouraged to improve how they travel by becoming AC. To add further encouragement, health is another factor that can be incorporated into commute monitoring.

\section{B. Health}

In many countries, including the UK, obesity is a growing health problem (NPHR, 2005) and promoting MIPA is a public health priority (Jones et al, 2012). The white paper 'Healthy Lives, Healthy People: Our strategy for public health in England', presented to the UK Parliament, claims that Britain is the most obese nation in Europe. Since the 1980s obesity has increased throughout all ages, groups and ethnicities (Frank et al, 2004).

A person's Body Mass Index (BMI) can be used to determine their physical state. An individual with BMI between 25 and 29 is considered overweight, and obese with a BMI of 30 and above (nhs.uk, 2013). UK statistics on obesity between 1993 and 2012 show that the proportion of adults which were overweight increased from $57.6 \%$ to $66.6 \%$ among men, and from $48.6 \%$ to $57.2 \%$ among women (National Statistics, 2014). With nearly one in four Britons being obese, there is increased possibility of health issues related to obesity (foa.org, 2013; National Statistics, 2012). Obesity is responsible for over 1.9 million deaths a year worldwide (Dora, 2007), it is associated with complications such 
as: high blood pressure, high cholesterol, asthma, arthritis and poor health status (Mokdad et al, 2001).

With over half of Britons estimated to be obese by 2050 (foa.org, 2013) one common suggestion to tackle the issue is appropriate MIPA. Increasing engagement of physical activity contributes to "achieving reductions in coronary heart disease and obesity, hypertension, depression and even anxiety" (Department of Health, 2009). UK data shows that $26 \%$ of women and $19 \%$ of men are considered inactive with only $37 \%$ of women and $46 \%$ of women reporting adequate MIPA (National Statistics, 2014). Guidelines to maintain healthy wellbeing and contribute to longer life recommend that adults must average more than 150 minutes of MIPA per week, while 60 minutes a day is recommended for children. Unfortunately, many in the UK do not meet these guidelines (NHS, 2013). Lack of physical activity is one of the many contributors to poor health and obesity, along with poor diet, but what causes physical inactivity in the first place? It can be noted here that research has found links between dominant private vehicle use and obesity (Lindstrom, 2007).

Walking or cycling has a number of benefits, from financial to health. Using public transport, such as busses and trains, can also be healthier and cheaper alternatives to private car use. Commute methods other than using private vehicle and that involve physical activity are known as active commuting methods. Those who choose to walk, cycle or use public transport to commute are considered as Active Commuters (AC).

Although many people attempt to keep healthy by jogging or attending a gymnasium, active commuting provides health benefits without the need for more sports/recreational facilities. Recreational physical activity could be associated with increased $\mathrm{CO} 2$ emissions due to private vehicles being used as transport to and from the location of the leisure activity (Goodman et al, 2012).

\section{Active Commuting}

Active commuting is one solution to the identified issues. Commuters can choose to use healthier and cheaper options with potential benefits on a personal level as well as global, if in the masses. This includes health benefits as method of transportation is significantly associated with poor health (Lindstrom, 2007). However there is not enough encouragement for commuters to seek different methods of transport, even though there are clear personal and global benefits.

A primary quantitative survey was conducted to confirm or deny results of national survey data against data collected locally. 50 participants completed an online or face-to-face questionnaire (24 and 26 participants respectively) to understand how they choose to commute, of which only $14 \%$ considered themselves to be AC. In addition to understanding levels of active commuting, further investigation was required towards mobile devices. The large popularity and uses of mobile devices mean many cannot do without them. For this reason participants were asked how important they considered their mobile devices, of which $84 \%$ considered them very important. Understanding the importance of mobile devices to users allowed to finally asking how encouraged they would be to choose active commuting methods if they were able to monitor their commute on their mobile device. Results show that $80 \%$ expressed some possible encouragement. This primary qualitative survey revealed scope and feasibility for development of an active commute tracker application with the aim to encourage active commuting.

\section{Application}

With the aim of encouragement and ownership of commuting, an application that can monitor users commuting habits would be appropriate. The usage of mobile devices has become increasing integral. Mobile device statistics show that $76 \%$ of users find mobile technology mostly useful (Statisticbrain.com, 2015).

There are a number of applications available for both Apple and Android devices that offer journey logging, such as Trip Journal by iQapps. However the number of travel based applications is very few, at around 4\% (Statisticbrain.com, 2015), with most designed for major travels and trips such as holidays, where users can post pictures and experiences to share with other app users. Existing tracking and navigation applications provide similar functionality to the proposed, taking up only $3 \%$ (Statisticbrain.com, 2015) of applications; however they focus mainly on providing basic navigation from origin to destination or track exercise routines - for joggers or runners.

An application that provides users with daily travel logs, together with health analysis based on method of travel could contribute towards AC. The application could also provide 'gamification' by giving users a point score for their commute. More points are earned for healthy method of transport. Such application leads to the following research question of interest: "If commuters are able to monitor and analyse their travel habits, would this encourage them to choose AC methods?"

\section{DEVELOPMENT}

Before development could begin it was important to choose the most suitable platform and operating system. Due to its high popularity, the Android operating system was chosen as the development platform (Rushton, 2012). Using the research gained so far, an Android application, Active Commute Tracker (ACT), was developed which is able to monitor log and analyse a user's travel habits. ACT allows users to view their journey timeline with components for health and ability to share data (Figure 1). The application autonomously collects user's movement speed and location to calculate the method of transport. Once the journey is complete the application calculates points earned from their method of transport. Users can then share this information with other users by uploading their scores to provide sense of encouragement for choosing healthier methods of transport. The application uses GPS location and pedometer (using device accelerometer) to calculate user speed and steps (through vibration). 


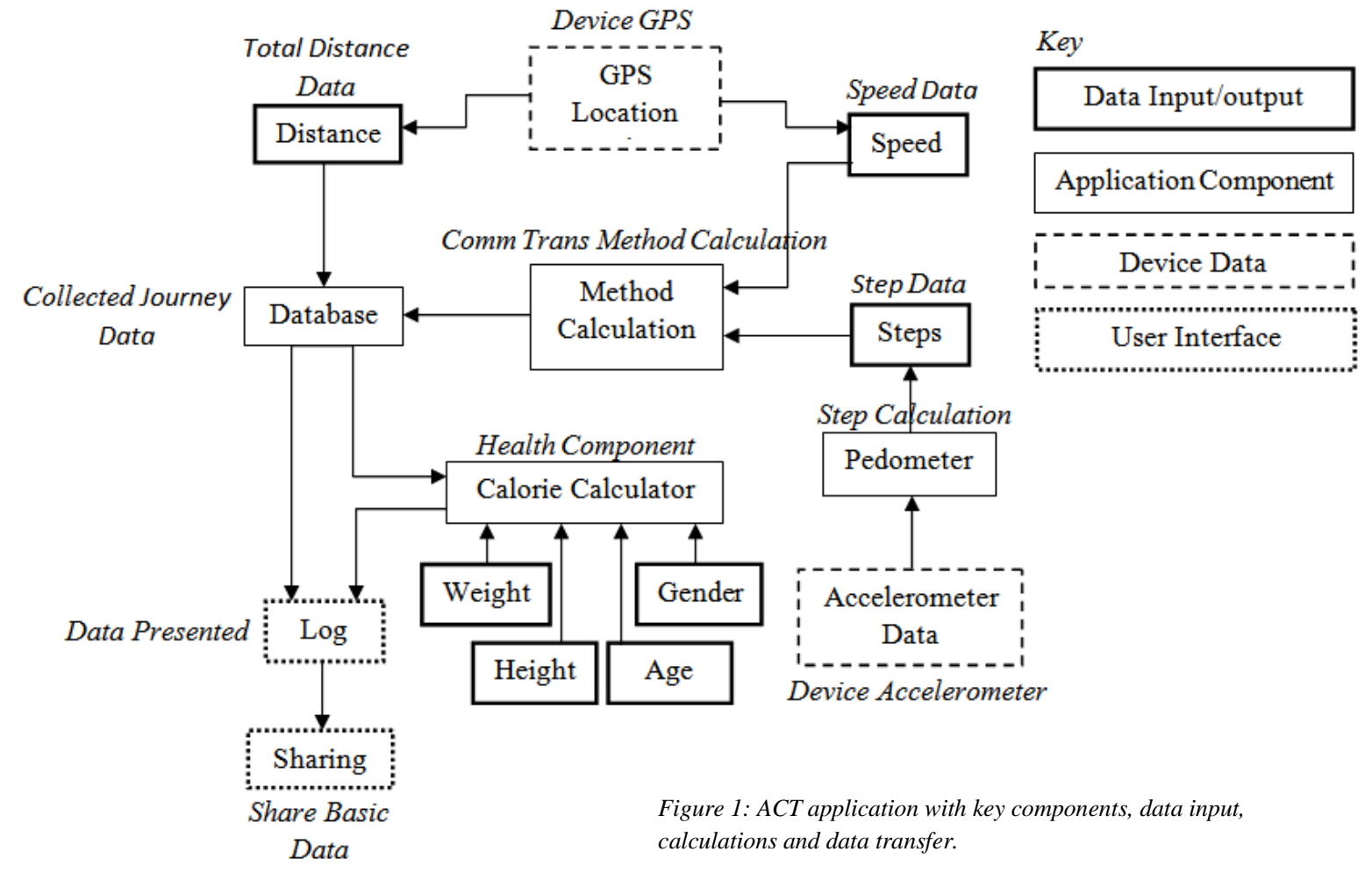

\section{Commute Transport Method Calculation Component}

The ACT application is able to calculate four different modes of travel: walking, jogging, running and motorised transport. Using the GPS for speed and pedometer for frequency of steps, ACT is able to calculate which mode is currently undertaken. This part of the application required extensive research into average walking, jogging and running speeds. Further research was required to understand average time between step cycles for walking, jogging and running. The step cycles average time check is used for users taking slower steps. Thus, if the average speed is between $0 \mathrm{~m} / \mathrm{s}$ and $2 \mathrm{~m} / \mathrm{s}$ then the user is most likely walking. However, if the average step cycle time is this slow and the speed exceeds $2 \mathrm{~m} / \mathrm{s}$ then the user is most likely using transport (and the application is registering up slow vibrations). Similar method was used to calculate more accurately whether the user is jogging, running or using transport. During the process of development for this component a Test Driven Development (TDD) was key to allow for checking the accuracy of method calculation allowing for adjustment in sensitivity in GPS data (for speed and distance) and Accelerometer data (for pedometer). With the relevant information the following rule based was incorporated to calculate Commute Travel Method.

- If speed is between $0 \mathrm{~m} / \mathrm{s}$ and $2 \mathrm{~m} / \mathrm{s}$ and the pedometer is registering successful step cycles then the user is recorded as walking;

- If speed is between $2 \mathrm{~m} / \mathrm{s}$ and $5 \mathrm{~m} / \mathrm{s}$ and the pedometer is registering successful step cycles then the user is recorded as jogging;
- If speed is between $5 \mathrm{~m} / \mathrm{s}$ and $7 \mathrm{~m} / \mathrm{s}$ and the pedometer is registering successful step cycles then the user is recorded as running.

- If speed exceeds $7 \mathrm{~m} / \mathrm{s}$ but successful steps are detected then the user is most likely using motorised transport.

Once this component had reached a high level of accuracy the development of the next component could begin.

\section{Health Component}

The data collected from the Commute Transport Method Component can then be used to calculate how many calories the user burned. The first part of the equation requires calculating the user's Basic Metabolic Rate (BMR) using the widely used and accepted Harris-Benedict formula (Roza \& Shizgal, 1984) based on the weight (WKG), height (HCM), and age (AGE):

\section{Male formula:}

$\mathrm{BMR}=(13.75 \times \mathrm{WKG})+(5 \times \mathrm{HCM})-(6.76 \times \mathrm{AGE})+66$

\section{Female formula}

$\mathrm{BMR}=(9.56 \times \mathrm{WKG})+(1.85 \times \mathrm{HCM})-(4.68 \times \mathrm{AGE})+655$

Once BMR is calculated it can be used to calculate the calories burned for each method of transport (MET) and duration of the activity (T).

\section{Calorie Burn:}

(BMR / 24) x MET x T 


\begin{tabular}{|l|l|l|l|l|l|l|}
\hline $\begin{array}{l}\text { Test } \\
\text { ID }\end{array}$ & $\begin{array}{l}\text { Method } \\
\text { Expected }\end{array}$ & $\begin{array}{l}\text { Step Timing } \\
(\text { Millisec })\end{array}$ & $\begin{array}{l}\text { Average } \\
\text { Speed } \\
(\mathrm{m} / \mathrm{s})\end{array}$ & $\begin{array}{l}\text { Max } \\
\text { Speed } \\
(\mathrm{m} / \mathrm{s})\end{array}$ & $\begin{array}{l}\text { Speed } \\
\text { Entered } \\
(\mathrm{m} / \mathrm{s})\end{array}$ & $\begin{array}{l}\text { Method } \\
\text { Recoded }\end{array}$ \\
\hline T3-01 & Walking & $<550 \& \& \Rightarrow>200$ & 1.70 & 2.00 & 1.70 & Walking \\
\hline T3-02 & Walking & $<550 \& \&=>200$ & 1,70 & 2.00 & 1,60 & Walking \\
\hline T3-03 & Walking & $>=550 \& \&<1500$ & 1.70 & 2.00 & 1.05 & Walking \\
\hline T3-04 & Walking & $>=550 \& \&<1500$ & 1.70 & 2.00 & 1.00 & Walking \\
\hline T3-05 & Jogging & $<550 \& \&=>200$ & 2.01 & 5.00 & 2.01 & Jogging \\
\hline T3-06 & Jogging & $<550 \& \&=>200$ & 2.01 & 5.00 & 3.00 & Jogging \\
\hline T3-07 & Jogging & $<550 \& \&=>200$ & 2.01 & 5.00 & 4.00 & Jogging \\
\hline T3-08 & Jogging & $<550 \& \&=>200$ & 2.01 & 5.00 & 5.00 & Jogging \\
\hline T3-09 & Running & $<550 \& \&=>200$ & 5.01 & 7.00 & 5.01 & Running \\
\hline T3-10 & Running & $<550 \& \& \Rightarrow 200$ & 5.01 & 7.00 & 5.50 & Running \\
\hline T3-11 & Running & $<550 \& \&=>200$ & 5.01 & 7.00 & 6.00 & Running \\
\hline T3-12 & Running & $<550 \& \& \Rightarrow 200$ & 5.01 & 7.00 & 6.50 & Running \\
\hline T3-13 & Running & $<550 \& \& \Rightarrow>200$ & 5.01 & 7.00 & 7.00 & Running \\
\hline T3-14 & Transport & - & $7.01<$ & - & 7.01 & Transport \\
\hline T3-15 & Transport & - & $7.01<$ & - & 10.00 & Transport \\
\hline
\end{tabular}

Table 1 (left): Commute Transport Method Calculation Component functional testing.

Table 2 (right): Health component functional testing.

This component together with the Commute Transport Method Component was tested with various user characteristics (see Table $1 \& 2$ ). The outcome tests the method calculation and calories burned calculation.

\section{Sharing Component}

Allowing users to post their main method of commute, the total duration and calories burned on social network sites such as Facebook provides an additional tool to encourage active commuting. Most users of Facebook already have most of their friends added to their contacts list. Additionally, Facebook has the ability to hide post from everyone, choosing whom to show individual updates specifically or to show updates to everyone. Furthermore, Facebook provides suitable API packages for use with Android and a personal Facebook Developers page that can be used to identify specifics of the application. For these reasons Facebook was decided to be used as sharing media for the users.

\section{TESTING}

Development of ACT was divided into three sections: tracker component, health component and sharing component. Each component was created individually and tested in a Test Driven Development (TDD) manner before being fused together to form a functioning prototype. Prototype testing could begin once the three main components of the application where successfully fused together and communicating with each other. At this stage of development, the application was tested for functionally of the application as a whole, which tested whether it met the user requirements and general functionality on the Android device. This was perhaps one of the longest phases of the project as the numbers of errors are high. This prototype was then tested for functionality of the three components and then went onto user testing.

\begin{tabular}{|l|l|l|l|l|l|l|l|l|}
\hline $\begin{array}{l}\text { Test } \\
\text { ID }\end{array}$ & Gender & Age & $\begin{array}{l}\text { Weight } \\
(\mathrm{kg})\end{array}$ & $\begin{array}{l}\text { Height } \\
(\mathrm{cm})\end{array}$ & Method & $\begin{array}{l}\text { Duration } \\
(\mathrm{sec})\end{array}$ & $\begin{array}{l}\text { Calculator } \\
\text { Calories }\end{array}$ & $\begin{array}{l}\text { Calories } \\
\text { Tester }\end{array}$ \\
\hline H1-01 & Female & 25 & 60 & 130 & Walking & 600 & 38 & 39.1 \\
\hline H1-02 & Female & 25 & 65 & 150 & Walking & 600 & 41 & 41.4 \\
\hline H1-03 & Female & 25 & 65 & 150 & Jogging & 600 & 70 & 71.8 \\
\hline H1-04 & Female & 25 & 65 & 150 & Running & 600 & 180 & 179.6 \\
\hline H1-05 & Female & 25 & 65 & 150 & Transport & 600 & 20 & 14.9 \\
\hline H1-06 & Female & 25 & 65 & 200 & Walking & 1200 & 85 & 85.5 \\
\hline H1-07 & Female & 25 & 65 & 200 & Jogging & 1200 & 149 & 150.8 \\
\hline H1-08 & Female & 35 & 85 & 150 & Walking & 1200 & 88 & 89.8 \\
\hline H1-09 & Female & 45 & 85 & 150 & Walking & 1800 & 128 & 129.8 \\
\hline H1-10 & Female & 55 & 85 & 150 & Walking & 1800 & 124 & 125.4 \\
\hline H1-11 & Male & 25 & 60 & 150 & Walking & 600 & 41 & 40.8 \\
\hline H1-12 & Male & 25 & 65 & 170 & Walking & 600 & 46 & 65.5 \\
\hline H1-13 & Male & 25 & 65 & 170 & Jogging & 600 & 91 & 91.4 \\
\hline H1-14 & Male & 25 & 65 & 170 & Running & 600 & 149 & 131.1 \\
\hline H1-15 & Male & 25 & 65 & 170 & Transport & 600 & 23 & 17.9 \\
\hline H1-16 & Male & 25 & 65 & 200 & Walking & 1200 & 100 & 99.4 \\
\hline H1-17 & Male & 25 & 65 & 200 & Jogging & 1200 & 200 & 198.9 \\
\hline H1-18 & Male & 35 & 85 & 170 & Walking & 1200 & 103 & 102.6 \\
\hline H1-19 & Male & 45 & 85 & 170 & Walking & 1800 & 74 & 55.6 \\
\hline H1-20 & Male & 55 & 85 & 150 & Walking & 1800 & 67 & 53.5 \\
\hline
\end{tabular}

\section{A. Functional Testing}

The first part involved testing the functionality of the three main components: tracker, health and sharing. These tests also helped confirm that the algorithms within the application, specifically its mains components, are processing the information collected successfully. Tables $1 \& 2$ show the result of such computations tests for the Commute Transport Method Calculation Component and the Health Component of ACT. Each test element tests for a certain criteria of the component. For example in table 1, T3-01 (Commute Transport Method Calculation Component testing, test batch $\mathbf{3}$, test number $\mathbf{0 1}$ ) tests that the method calculator is able to successfully calculate the users transport Method based upon Step Timing cycle (time difference between each step) together with the users traveling Speed. Each following test (T3-02, T3-03...) preforms a similar test with a different speed and step cycle input to present the transport method. Similarly, the health component is tested using the same principles. For example in table 2, H1-01 (Health Component testing, test batch 1, test number 01) tests that the calories calculated based upon the users inputted (through ACT settings) Gender, Age, Weight and Height, together with the transport Method and Duration, is similar to that of a reputable calorie calculator. The online calculator used was the Activity Based Calorie Burn Calculator at http://www.shapesense.com. These tests confirm that the calories burned calculated by the Health Component similar figures to that calculated by an online based calculator, based on the different information entered.

\section{B. $\quad$ Prototype Testing}

The previous testing phase required data to be inputted manually (hard coded) to check functionality and that the required output was achieved. Once the functionality of the components met the requirements independently (verified through testing), the functionality of the prototype with all the components put together can be tested. However the prototype testing inputs data that is collected from the mobile device sensors, using internal GPS and 


\begin{tabular}{|c|c|c|c|c|}
\hline \multicolumn{2}{|l|}{ 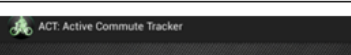 } & Test ID & \multicolumn{2}{|c|}{$\begin{array}{l}\text { PT-08 } \\
\text { Nexus } 7\end{array}$} \\
\hline \multicolumn{2}{|l|}{ 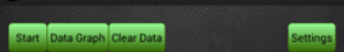 } & & $\frac{\mathrm{N}}{\mathrm{Actua}}$ & Record \\
\hline \multirow[b]{2}{*}{ speed } & \multirow{3}{*}{$\begin{array}{c}0 \mathrm{kph} \\
0 \mathrm{mph}\end{array}$} & Steps & 100 & 92 \\
\hline & & Current Method & Walking & Walking \\
\hline \multirow[b]{2}{*}{ Steps: } & & Main Method & Walking & Walking \\
\hline & 92 & Travel Distance & & $95 \mathrm{~m}$ \\
\hline \multirow[t]{2}{*}{ Method } & \multirow{4}{*}{$\begin{array}{r}\text { Walking } \\
95 \text { meters } \\
0.06 \text { miles }\end{array}$} & Speed & - & - \\
\hline & & Calories & - & $6 \mathrm{cal}$ \\
\hline Dist. & & Points & - & 79 \\
\hline $\cos 20=0$ & & Duration & - & $2 \min$ \\
\hline 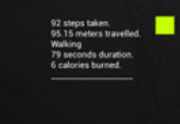 & 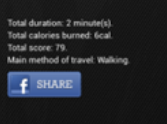 & \multicolumn{3}{|c|}{$\begin{array}{l}\text { Comment } \\
100 \text { steps taken walking. Fully detected. } \\
\text { Correct main method and overall record. Steps } \\
\text { less than actual - pedometer sensitivity. }\end{array}$} \\
\hline
\end{tabular}

Figure 2 (left): Prototype testing for correct transport method calculation and step count (pedometer).

Figure 3 (right): Prototype testing for correct transport method calculation using mixed methods with sharing.

accelerometer. There are a number of elements of the prototype which needed to be tested, these where; correct distance calculation, correct duration, correct transport method calculation, correct calories burned calculation and the simple points system. All of these elements must provide somewhat reliable outcomes. Another test is that the results should not differ drastically from device to device. All tests have the same weight, height, age and gender details. For example in figure 2, PT-08 (Prototype Test, test number $\mathbf{0 8}$ ) tests a user walking 100 steps with ACT enabled in their device. ACT records the data and presents it to the user. Through this testing it was clear that the pedometer sensitivity was an issue, differing user to use and device to device. To counter this issue, an option for pedometer sensitivity was introduced through ACT application settings. Similarly, figure 3 shows test PT-16 (Prototype Test, test number 16) which tests a mixture of walking and motorised transportation (private vehicle) transport method. Additionally, PT-16 includes a test for the sharing capability, showing only basic information on popular social network, Facebook.

\section{User Testing}

After the prototype was tested and functionality met requirements, the application was sent to a number of volunteer testers who would run the application on their device and fill in a test feedback form. All testers were given a feedback form to fill in to reflect on their experience of ACT during the course of the testing period. This phase was two purposes; to test functionality on user devices and for user feedback on encouragement towards becoming AC. At the early stages of user testing, some users faced issues with the sharing component which did not allow them to post on Facebook. This was quickly resolved. Another user mentioned that there was an issue with the GPS signal. The user was finding is difficult to obtain this signal and was not able to start ACT, as it requires GPS signal before the commute can be recorded. The problem was due to the user starting the application

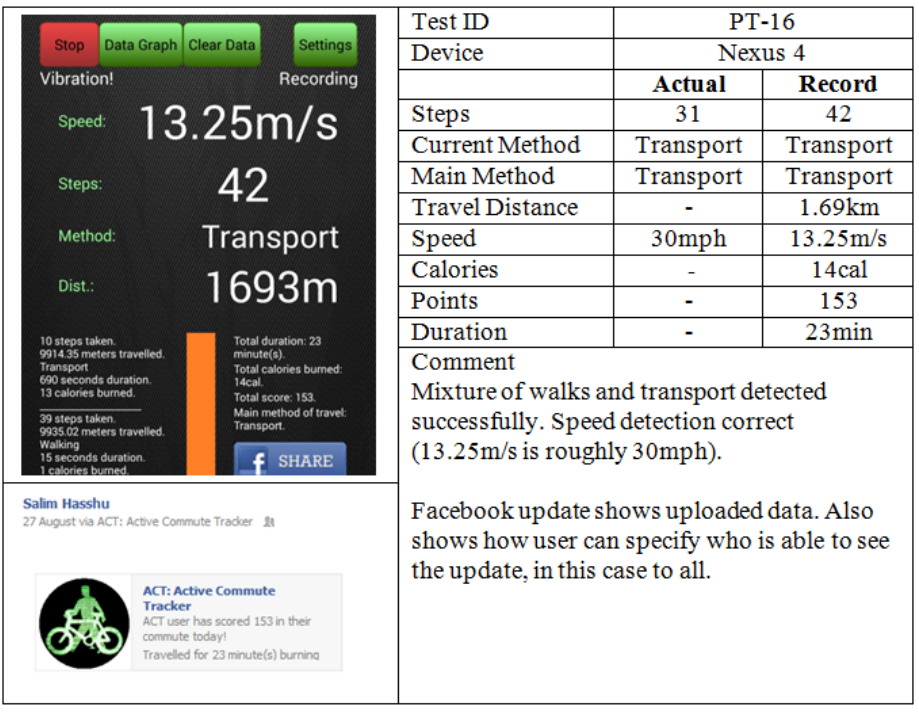

whilst still being indoors (poor GPS signal). However, it functioned correctly once a signal was received.

All testers were given a feedback form to fill in to reflect on their experience of ACT during the course of the user testing period. The feedback form consisted of questions which question ACT's usability as well as its fit for purpose. The results are discussed below.

\section{RESULTS}

Most testers found that ACT was easy to use and that the UI was understandable and simple. The majority of testers agreed to ACT functioning well on their device however some disagreed (see figure 4, Question 1). This was in most cases due to sharing, GPS and UI issues during early testing. These issues were resolved following the corresponding users' feedback.

All the testers who were able to test the application pedometer and commute method detection found that it was fairly accurate in counting steps and detecting method (see figure 4, Question 4 \& 5). A very small number of testers provided feedback on the calories part of ACT. Most of them did not use alternative health application or calorie calculators to compare against ACT; however a small number provided positive feedback.

From those testers who were able to test the ACT application found it to be useful in monitoring their commutes. All testers were able to answer whether an application of this nature would be useful. The majority of testers (75\%) agreed that an application of this nature was 'useful' or 'very useful' (see figure 4, Question 7). However those who could not answer this question (selecting N/A) was due to earlier GPS and UI issues, confirmed by tester comments, which has since been rectified. Similar results are seen when asking if ACT encourages towards becoming an AC (see figure 4, Question 8). Again those which have selected 'Neither' (25\%) reflects the number of users who had functional difficulty. 
Q1: Was the ACT: Active Commute Tracker application easy to use?

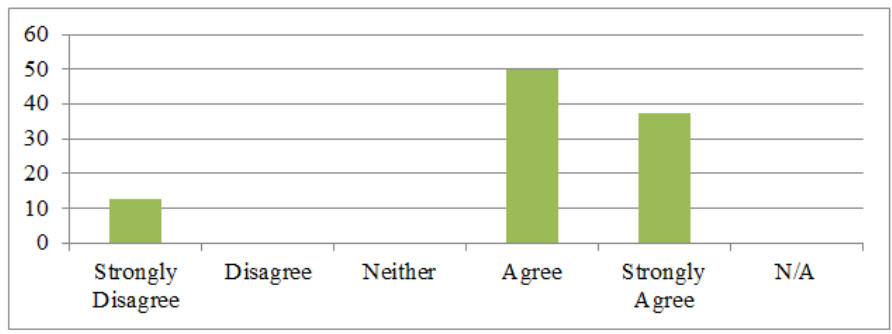

Q4: How accurate did you find the pedometer?

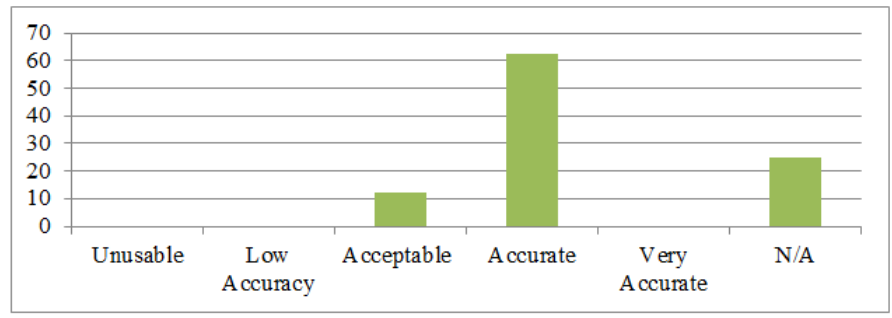

Q5: How accurate did you find the method of travel to be?

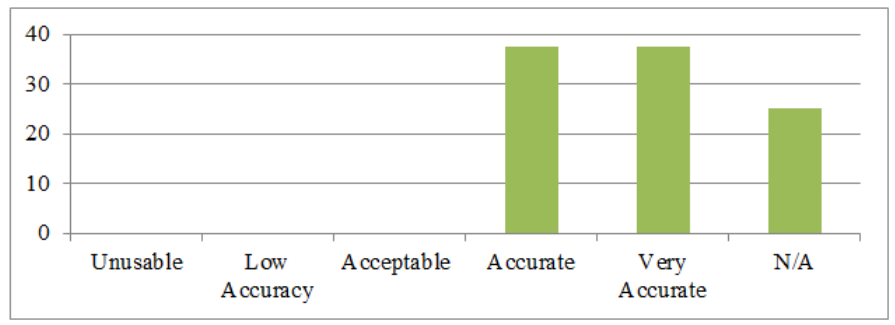

\section{CONCLUSION}

An application that monitors users' commute is most likely to aid in encouraging commuters to choose active commuting methods. However, it is important to have good functionality and user interface as many of those who did not feel encouraged by ACT were a result of the application unable to function on their device. Fortunately, none of the testers felt discouraged towards active commuting as a direct result of the application. Many of the testers contacted expressed concerns over the application's GPS location tracking and felt discouraged, as they did not wish for their location to be monitored. However ACT did not store location and this was explicitly expressed to all testers before participating in testing. Although some testers did upload their commute data online, there was a distinct lack of enthusiasm for this feature, perhaps due to the chosen sharing option (Facebook).

Overall the ACT application highlights some area of research and development that can be welcome by mobile users. The application was able to successfully monitor commute method, provide health data and allow sharing for users. No feedback received showed any strong discouragement towards an application of this nature; however some issues need to be addressed for further development in this field.
Q7: How would you rate the usefulness of this application?

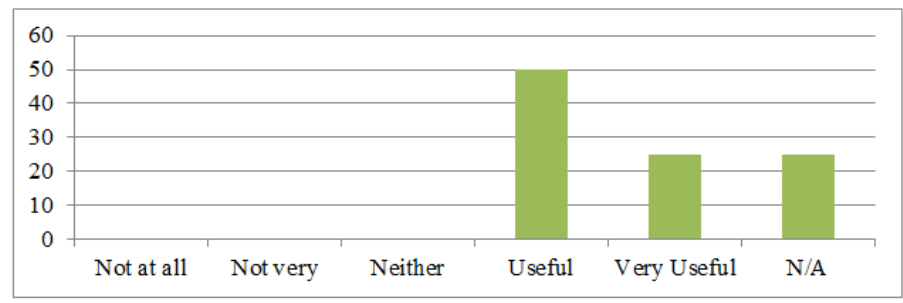

Q8: Does this application encourage you towards becoming an active commuter?

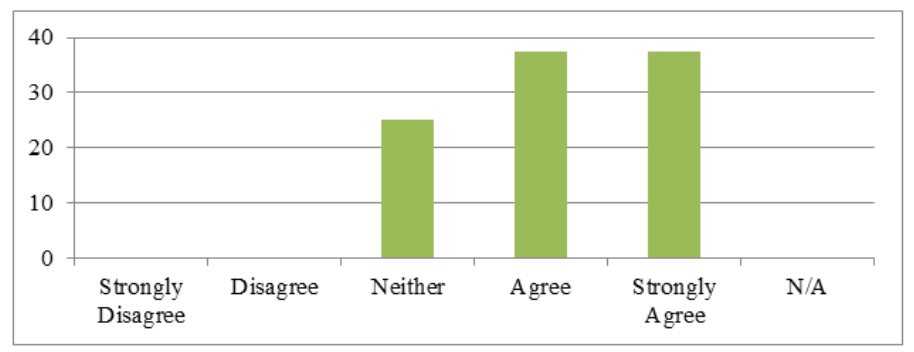

Figure 4: Graphical representation of ACT application user testing feedback form for questions; 1, 4, 5, 7 and 8 .

\section{FUTURE RESEARCH}

Encouraging features could be added to the ACT application. If detailed analysis of a user's commute habits during the course of a week has been stored, the application could suggest healthier AC options. By analysing the route taken by the user to their regular destination, duration and time, the application could suggest alternatives such as cycle routes, bus routes or train use that would healthier for the user. This, however, would require precise location tracking and storing of this data as well as access to up to date bus and train schedules.

\section{REFERENCES}

[1] Batterbury, S.P.J. (2003). Environmental activism and social networks: campaigning for bicycles and alternative transport in West London. Annals of the American Academy of Political and Social Science 590, pp.150-169.

[2] Bergstad, C. J., Gamble, A., Hagman, O., Polk, M. \& Garling, T. (2011). Affective-symbolic and instrumental-independence psychological motives mediating effects of socio-demographic variables on daily car use. Journal of Transport Geography, Vol. 19(1), pp.33-38.

[3] Cameron, I., Kenworthy, J.R. \& Lyons, T.J. (2003). Understanding and predicting private motorised urban mobility. Transportation Research Part D: Transport and Environment, Vol.8, pp.267-283. 
[4] Department Of Health. (2009). Be Active: Be Healthy: A plan for getting the nation moving, Department of Health in partnership with other Government Departments.

[5] DfT, Department For Transport, (2011). 'Commuting and Business Travel', Great Britain, National Statistics, pp 1-3.

[6] Dora, C. (2007). Health burden of urban transport: The technical challenge. Sadhana, 32(4), pp.285-292.

[7] FOA.ORG, (2013). The State of Food and Agriculture, [online] Available at: http://www.fao.org/docrep/018/i3300e/i3300e.pdf [Accessed 6 Jul. 2014].

[8] Frank, L. D., Andresen, M.A. \& Schmid, T. L. (2004). Obesity Relationships with Community Design, Physical Activity, and Time Spent in Cars, American Journal of Preventive Medicine, 27(2), pp.8795 .

[9] Gardner, B. \& Abraham, C. (2007). What drives car use? A grounded theory analysis of commuters' reasons for driving, Transportation Research Part F: Traffic Psychology and Behaviour, Vol.10(3),pp.18200.

[10] Goodman, A., Brand, C. \& Ogilvie, D. (2012). Associations of health, physical activity and weight status with motorised travel and transport carbon dioxide emissions: a cross - sectional, observational study. Environmental Health 2012. Vol.11(52).

[11] Government Office For Science, (2007). Tackling obesities: future choices - Summary of key messages, reducing obesity: future choices, research and analysis.

[12] Hmg, Hm Government. (2010). Healthy Lives, Healthy People: Our strategy for public health in England, CM7985.

[13] Jones, C. \& Ogilvie, D. (2012) Motivations for active commuting: a qualitative investigation of the period of home or work relocation, International Journal of Behavioral Nutrition and Physical Activity 2012, 9:109.

[14] Lindstrom, M. (2007). 'Means of transportation to work and overweight and obesity: A population-based study in southern Sweden', Preventive Medicine, 46, pp.22-28.

[15] Metz, D, (2008), 'The limits to travel: How far will you go?'. London: Earthscan.

[16] Mokdad, A. H., Ford, E. S., Bowman, B. A., Dietz, W. H., Vinicor, F., Bales, V. S. \& Marks, J. S. (2001). Prevalence of obesity, diabetes, and obesity-related health risk factors, JAMA, Vol.289(1), pp.76-79.

[17] Mokhtarian, P.L. \& Salomon, I. (2001). How derived is the demand for travel. Some conceptual and measurement considerations. Transportation Research Part A, Vol.35, pp.695-719.

[18] Mokhtarian, P.L., Salomon, I. \& Redmond, L.S. (2001). Understanding the demand for travel: its not purely derived. Innovation, Vol.14(4),pp. $355-380$.

[19] National Statistics. (2012). Health Survey for England 2012: Health Social Care and Lifestyles, Health and Social Care Information Centre.

[20] National Statistics. (2014). Statistics on Obesity, Physical Activity and Diet: England 2014, Health and Social Care Information Centre.

[21] Nhs, The Health And Social Care Information Centre. (2013). Statistics on Obesity, Physical Activity and Diet: England 2013, 2, UK.

[22] NPHR, National Public Health Report. (2005). 'National Board on Health and Welfare', UK.

[23] Nutristrategy.com, 'NutriStrategy - Examples of Calories Burned During Exercise, Running, Swimming, Walking to Weightlifting', 2013. [Online]. Available: http://www.nutristrategy.com/activitylist3.htm. [Accessed: 13 Jun 2013].

[24] Ortuzar, J. D., \& Willumsen, L.G. (1999). Modelling Transport, 2nd ed., John Wiley, New York.

[25] Roza A. \& Shizgal, H, D (1984) The Harris Benedict equation reevaluated: resting energy requirements and the body cell mass, The American Journal of Clinical Nutrition, pp 168-182.
[26] Rushton, K. (2012). 'Number of smartphones tops one billion', The Telegraph, 17 October 2012.

[27] Statisticbrain.com, (2015). Mobile Device / Cell Phone Statistics | Statistic Brain. [online] Available at: http://www.statisticbrain.com/mobile-device-cell-phone-statistics/ [Accessed 14 Apr. 2015].

[28] Statisticbrain.com, (2015). Mobile Phone App Store Statistics | Statistic Brain. [online] Available at: http://www.statisticbrain.com/mobilephone-app-store-statistics/ [Accessed 14 Apr. 2015].

[29] Steg, L. (2004). Car use: lust and must. In: T. Rothengatter \& R.D. Huguenin (Eds.), Traffic and Transport Psychology: Theory and application, pp. 443-452. Amsterdam: Elsevier.

[30] Wen, L.M., Millett, C., Orr, N., \& Rissel, C. (2006). Driving to work and overweight and obesity: findings from the 2003 New South Wales Health Survey, 30 (5), 782-786. 